\title{
In-hand manipulation (IHM) in children 6 and 7 years of age: A follow-up study
}

\author{
Marieta Visser, B OT (UFS), MSc OT (Wits) \\ Lecturer, Department of Occupational Therapy, Faculty of Health Sciences, University of the Free State
}

Mariette Nel, BA (with Urbanology), BA (Hons), M Med. Sc Biostatistics (UFS)

Lecturer, Department of Biostatics, Faculty of Health Sciences, University of the Free State

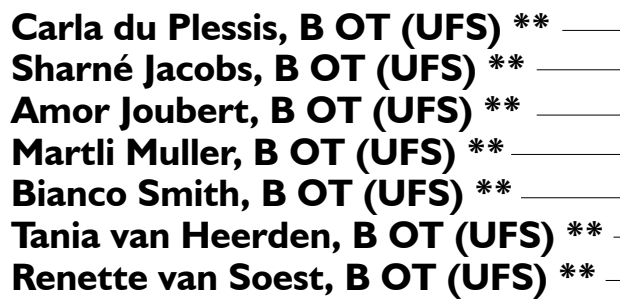

** Students in the Department of Occupational therapy at the University of the Free State the time the study was carried out

Background and aim: No comprehensive, standardised measureing instruments with age-related norms, to evaluate all IHM components, are currently available, causing difficulty with regard to accurate assessment and intervention planning. This lack of a context-specific, valid and reliable measure in the field of paediatrics remains a challenge for South African occupational therapy clinicians The aim of this study was therefor to investigate the IHM skills in six-and seven-year-old children in Bloemfontein, South Africa.

Methods: A quantitative descriptive study was conducted by using video footage of each child in the study performing the activities on the Free State University In Hand Manipulation (FSU IHM) Checklist, and scoring their performance.

Results: One-hundred and fifty-eight children in the age group 6-7 years participated in the study. Results indicated that most children in both these age groups could perform translation, simple and complex rotation, and shift with stabilisation. However, complex rotation with stabilisation was more difficult for both age groups. Compensatory methods were mostly used in combination by both age groups.

Conclusion: The results from this study could be combined with those obtained for four and five year children in a previous study, to develop base-line IHM standards for children aged four - seven years, to inform clinical decision making and practice. The Free State University In Hand Manipulation (FSU IHM) Checklist provides occupational therapists with a comprehensive, inexpensive instrument for the assessment of all IHM components, which is easily reproducible and quick to administer. The checklist is not yet generalisable to the South African population but can serve as an interim measure. Further development of the checklist is recommended.

Key words: In-hand manipulation; assessment; translation; rotation; shift

\section{INTRODUCTION}

The lack of context-specific, valid and reliable norm-referenced measuring instruments for hand function in children remains a challenge to occupational therapists in South Africa. Measuring instruments used by South African occupational therapists are often either standardised on populations from developed countries, not affordable, or an instrument for measuring a specific outcome does not exist.

In terms of in-hand manipulation (IHM), no comprehensive standardised measuring instruments with age-related norms to evaluate all IHM components, are currently available. Although several researchers ${ }^{1-6}$ have aimed to address this matter, occupational therapy clinicians in the field of paediatrics continue to communicate their need for an IHM measuring instrument. Visser et $\mathrm{al}^{6}$ reported that "as a result of the lack of measuring instruments with age related norms regarding IHM, therapists are not aware of what can be expected of specific age groups in terms of IHM, causing difficulty with regard to accurate assessment and intervention planning"6:22. This situation creates challenges for evidence-based practice in occupational therapy.

Although it would be beneficial to develop and standardise a comprehensive IHM measurement instrument on the SA population, this is a costly and lengthy process. In the meantime, collective evidence based on smaller studies, could provide base-line norms to inform clinical decisions regarding IHM and for further research. Crucial ages in the development ${ }^{7}$ and mastering ${ }^{8,9}$ of IHM skills have been identified as the ages between four and seven years. During this stage, children also develop other refined hand skills needed for school readiness activities, and consequently, early detection of IHM difficulties become essential.

Baseline measurement levels for IHM skills of four- and fiveyear-old South African children have been published ${ }^{6}$. The aim of the current study was to inform clinical practice by reporting on research findings of all components of IHM for six- and seven-yearold children. The study provides clinicians with a comprehensive overview of IHM for this age group on the Free State University In Hand Manipulation (FSU IHM) Checklist that is inexpensive, easily reproducible and quick to administer. 


\section{LITERATURE REVIEW}

In the literature review IHM is conceptualised, followed by an overview of the assessment of IHM.

\section{Conceptualising in-hand manipulation}

Occupational therapists play an essential role in the assessment and treatment of people with hand function deficits. Hand function is dependent on client factors ${ }^{10}$ such as muscle strength, sensation, range of motion and control of voluntary movement including fine motor control which supports the ability to achieve various grips and grasps, and IHM". In-hand manipulation is defined as the "process of using one hand to adjust an object for more effective object placement, or release; the object remains in that hand and usually does not come in contact with a surface during IHM"2:35 According to the Occupational Therapy Practice Framework III (OTPF III), performance skills are "goal directed actions that are observable as small units of engagement in daily life occupations" $10: 57$ and are learned and developed over time. Motor skills such as the performance of grips, manipulation, calibration and co-ordination are observed in the performance of IHM, and are required for performance in all areas of occupation where hand function plays a role ${ }^{10}$.

According to Exner ${ }^{3}$ and for the purpose of this research, IHM skills can be clustered into three components, namely translation, shift and rotation. In-hand manipulation can occur with or without simultaneous stabilisation of materials in the other hand $^{8}$. The components of IHM include:-

* Stabilisation occurs when one or more objects or parts of objects are held in the ulnar aspect of the palm so that the thumb and radial fingers can participate in another hand skill ${ }^{3: 39}$.

$*$ Translation is defined as the movement that either begins or ends on the finger pads distal to the distal interphalangeal joints ${ }^{3}$. Translation is divided into finger-to-palm and palm-tofinger translation.

Finger-to-palm translation occurs when an object is held by the distal finger surface and the pad of the thumb and moved into the palm proximal to the metacarpal-phalangeal joints ${ }^{3}$. An example of this movement would be to pick up a coin with the fingers and thumb and move it into the palm of the hand ${ }^{8}$. Palm-to-finger translation occurs when objects are moved from the palm to the distal finger surface. The thumb is active in producing object movement, and it moves from a pattern of flexion to extension ${ }^{3}$. An example of this movement would be to move a coin from the palm of the hand to the finger pads before placing it in a vending machine ${ }^{8}$.

$*$ Shift is defined as the "refinement of placement of the object against the fingers and thumb"8:284. It occurs at the finger and thumb pads with alternation of thumb and (usually radial) finger movement ${ }^{8}$. An example of this movement would be separating pages when paging through a book ${ }^{8}$.

* Rotation is defined as the movement of an object around one or more of its axes ${ }^{\prime \prime}$. It is further described as a movement that occurs at or near the pads of the fingers ${ }^{3}$. Rotation is divided into simple rotation and complex rotation.

Simple rotation is a movement that occurs when an object is turned between the finger pads and thumb pad in an alternation movement between thumb and fingers ${ }^{3}$. The movement may occur with only the index finger and the thumb or with the involvement of additional fingers. An example of this movement would be to unscrew a small bottle cap ${ }^{8}$.

Complex rotation is a movement involving rotation of the object or rotation that requires isolated, independent movements of the fingers and/or thumb $\mathrm{b}^{3}$. The movement is further described as the object being turned between 180 to 360 degrees. An example of this movement would be to turn over a pencil to use the eraser ${ }^{8}$.

Children experiencing problems with IHM often display efficient hand function (reach, grasp, release) which is required to perform basic activities. However, the execution of more complex tasks requiring refined manipulation of objects and materials, including tool use such as cutting with scissors, dressing when buttons need to be manipulated, independent eating skills which require adjusting eating utensils and managing finger foods and rotating the pieces of a puzzle in constructive play and table top games, seem laborious or poor. In order to compensate for poor IHM, children often use both hands for manipulation (when only one hand is required), often drop the materials and objects they are manipulating, and use forceful pushing and pulling when handling materials, which may result in materials breaking. Children with poor IHM tend to avoid fine motor activities, leaving them with fewer opportunities for practice, resulting in their feeling incompetent, which may negatively influence a child's acceptability to others.

\section{Evaluation of in-hand manipulation}

Children are frequently referred to occupational therapy for deficits in hand function or fine motor skills. To determine the origin of the deficits, a comprehensive evaluation of all the underlying components of hand function is important. Therefore, the occupational therapist needs to understand the typical development of all these underlying components in order to interpret observations and make appropriate recommendations.

Although literature describing the development of each separate component of IHM and age norms for IHM is limited, in-hand manipulation has been described in relation to variables related to the development of IHM $\mathrm{IM}^{3,7,8,12-14}$, the age at which IHM skills emerge and are mastered ${ }^{3,8}$, rapid periods of development ${ }^{8,9}$ and possible gender differences ${ }^{5,15}$.

When considering the age at which IHM skills emerge and are mastered Exner ${ }^{3}$, reports that IHM skills develop between the ages of 18 months and seven years, and are refined until the age of nine to ten years. These skills should be fully developed by the age of 12 years ${ }^{8}$. Of importance for this study is that at the age of six years, children are able to make use of stabilisation in conjunction with aspects of the other IHM components ${ }^{5}$. The consistent use of IHM components in combination such as palm-to-finger with stabilisation followed by rotation with stabilisation is expected in children aged six and seven years old ${ }^{8}$.

Several IHM tests have been published such as the Test of InHand Manipulation (TIMS) ${ }^{16}$, Test of In-Hand Manipulation (TIME) by Exner ${ }^{3}$, the In-Hand Manipulation Test (IMT) by Miles Breslin and Exner ${ }^{4}$, the Test of In-Hand Manipulation (TIHM) (also known as the Nine-hole-peg board test) by Case-Smith ${ }^{9}$, the unnamed test by Pehoski et $\mathrm{al}^{5}$, the Observation Protocol on in-hand manipulation and functional skill development by Humphry et $\mathrm{al}^{17}$ as well as Benbow's informal checklist ${ }^{18,19}$.

Most of these tests do not have psychometric evaluations and no normative data for IHM were published for any of these tests ${ }^{6}$. Only the Test of In-Hand Manipulation (TIHM) ${ }^{9}$ has been researched thoroughly for construct validity but this test does not cover all aspects of IHM. The researchers therefore developed a practical, simple and cost-effective measuring instrument to evaluate all the aspects of IHM in children in South Africa using a comprehensive observation checklist, described in a previous publication on the development of the FSU IHM Checklist ${ }^{6}$.

This current study formed part of a larger quantitative descriptive one in which IHM skills in children of South Africa were described. The aim of this part of the study was to describe all aspects of IHM skills with regard to translation, rotation and shift movements in six - and seven-year-old children in Bloemfontein, South Africa to extend the age band data for the FSU IHM Checklist.

\section{METHODS}

\section{Study population}

The names of 48 primary schools in the Mangaung (larger Bloemfontein) area were obtained from the Department of Basic Education Free State Provincial Department. These included private 
and public schools of various socio-economic status and cultural backgrounds. Forty-two of these schools had contact details and were contacted telephonically and received faxed/e-mailed information letters regarding the proposed research study. Of these 42 schools only eight schools responded, agreed to participate or met the inclusion criteria of English as the primary language of education set for this study.

\section{Sampling procedures}

Proportional randomised sampling using class lists from the eight participating schools, was done, and 200 children were randomly selected from the eight schools. These selected children's parents or caregivers received an information letter, consent document and a parent questionnaire to determine whether the children met the inclusion criteria.

\section{Inclusion and exclusion criteria}

The inclusion criteria for the study were applied to the feedback from the parent questionnaire and required that children be aged six or seven years old and have English as their primary language of education regardless of their home language and culture. Inclusion and exclusion criteria similar to those set in the previous study ${ }^{6}$ were used for the selection of the children. Consequently, in this study only children taught in English and who could understand it were included in the study. This was to allow for the administration of the FSU IHM Checklist in English. This meant that children from different language groups, more representative South African sample were excluded. However, it is worth mentioning that most schools in Bloemfontein where English is the language of education, constitute a multicultural group of children.

Children were excluded if they had any physical, cognitive or emotional disabilities as a result of diagnosed conditions such as autism, cerebral palsy and visual impairment. They were also not included in the study if their parents had not given consent, the children did not assent to participate in the study, or it was indicated in the parent questionnaire that they had previously received or were currently receiving occupational therapy intervention for IHM and/or hand function difficulties. Of the 200 children that were selected, I 58 children responded and met the inclusion criteria. The group of participants consisted of 58 six-year and 100 sevenyear-old children.

\section{Measuring instrument}

\section{Parent questionnaire}

The parent questionnaire consisted of questions related to the children's pre-primary school history, language proficiency, health, development, and indications of any medical, developmental, behavioural, or scholastic concerns that could influence their performance in an IHM activity.

\section{The Free State University In Hand Manipulation (FSU IHM) Checklist}

The FSU IHM Observation Checklist was developed from nonstandardised activities and standardised tests published in the literature to ensure the assessment of all the components of IHM. A short description of each activity, photographs of these activities and the scoring of the UFS IHM Observation Checklist is presented in Table I.

Adaptations in the FSU IHM Observation Checklist were made for this study based on recommendations from the previous study and included an item for palm-to-finger translation as well as the instructions for each activity on the checklist to make it more user friendly.

\section{Data collection procedure}

A pilot study conducted on five children (three six-year and two seven-year-olds) from a randomly selected participating school indicated that no further changes needed to be made to any of the forms and activities used during the assessment procedure.
In order to ensure rigour in the assessment procedure, the researchers had requested a room at each of the eight schools that met specific requirements. This included sufficient lighting, equipped with a small table and chair suitable for a child of six to seven years old and in a quiet area. Prior to each child's assessment, the researchers had to ensure that the room met the requirements and that the child was positioned correctly.

All the student researchers participated in data collection, two being allocated to each school. The first researcher informed the child about the research, the assessment procedure and asked him/her to give assent by crossing a block on the form. The assessment procedure consisted of a demonstration by the first researcher, followed by an opportunity for the child to practise, with the purpose, of eliminating "the possible variable of unfamiliarity influencing task performance" $"$ : 3 . The child then completed the eight tasks after which he/she was asked to draw a picture on the back of the assent form to determine which pencil grasp he/she used.

The second researcher was responsible for the production of video footage of each child's upper body and hands, using a Sony digital video camera recorder, Model Number DCR-SR2 IE, I800 $x$ Digital Zoom, 67 x Extended Zoom, stabilised on a tripod stand. The code allocated to each child's checklist was used on the corresponding video footage in order to ensure confidentiality. The video recording included the introduction of the research to the child but did not include the practice opportunity, and only continued when the child performed the actual scored assessment.

Afterwards, the video footage of each child was scored separately by two researchers who were not part of the child's assess-

\section{Table I: Description of the UFS IHM Observation}

\begin{tabular}{|l|l|}
\hline Task I & $\begin{array}{l}\text { Complex rotation: The child removes five dowels } \\
\text { from the holes in the peg board, one at a time. Using } \\
\text { their fingertips the child was expected to turn the } \\
\text { dowels } 180^{\circ} \text { and replace the dowels in their original } \\
\text { hole. To avoid confusion, one end of the dowel was } \\
\text { painted blue/red. }\end{array}$ \\
\hline Task 2-5 & $\begin{array}{l}\text { Finger-to-palm and palm-to-finger translation: } \\
\text { The child picks up as many dowels as possible and while } \\
\text { holding them within the palm, placed them in the peg } \\
\text { board one at a time. }\end{array}$ \\
\hline Task 6 & $\begin{array}{l}\text { Shift with stabilisation: The child picks up two coins } \\
\text { and places them in the piggy bank slot, one at a time. }\end{array}$ \\
\hline Task 7 & $\begin{array}{l}\text { Simple rotation: Child holds a coin horizontally and } \\
\text { rotating it with the fingertips I80 for four consecutive } \\
\text { rotations. }\end{array}$ \\
\hline Task 8 & $\begin{array}{l}\text { Complex rotation with stabilisation and shift } \\
\text { components: The researcher places two dowels on } \\
\text { the ulnar aspect of the child's palm. The child moves } \\
\text { one of the dowels to the fingertips for rotation while } \\
\text { holding the other dowel in the palm. }\end{array}$ \\
\hline
\end{tabular}

The test consisting of all eight tasks takes approximately 10-15 minutes to complete, including the practice round.

The equipment for UFS IHM Observation activities consisted of those suggested for the TIHM:

- a nine-hole peg board

- (100 x $100 \times 20 \mathrm{~mm})$ with 9 holes (15 × $7 \mathrm{~mm}, 32 \mathrm{~mm}$ apart $)$,

- 9 dowels $(32 \times 7 \mathrm{~mm})$

- a plastic container

$(100 \times 100 \times 20 \mathrm{~mm})$

The non-standardised activities consisted of:

- three two Rand coins,

- a piggy bank

- two dowels.

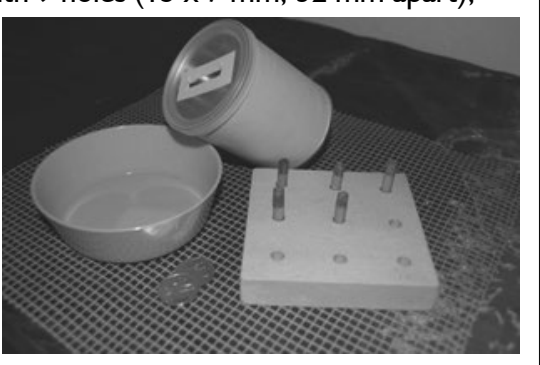


ment process and inter-rater reliability was established. The coding of each checklist was cross-checked.

\section{Data analysis}

Descriptive statistics, namely frequencies and percentages for categorical data and medians and percentiles for continuous data, were calculated. The data analysis for this paper was performed by using the Statistical Analysis System (SAS) software.

\section{Ethics}

Approval for the study was obtained from the Ethics Committee of the Faculty of Health Sciences at the University of the Free State. To ensure ethical conduct, written consents were received from the Department of Basic Education Free State Provincial Department, principals and teachers of the eight participating schools. Written consent was received from parents of the participants to include video footage, and assent was given by each of the participating children prior to the study.

\section{RESULTS}

\section{Demographics}

Data indicated that, $58(36.7 \%)$ children were six years of age, of whom $20(34.5 \%)$ were male. One-hundred $(63.3 \%)$ children were seven years of age, with $52(52.0 \%)$ being male. With regard to hand preference, 49 (84.5\%) of the six-year-olds and 91 (91.0\%) of the seven-year-olds presented with right hand dominance. An efficient pencil grasp was observed in 57 (98.3\%) of the six-yearolds and in 94 (94\%) of the seven-year-olds. For the purpose of this study an efficient pencil grasp was defined as a grasp where an open web space was present and included a tripod, quadruped and adapted grip, as described by Benbow ${ }^{19}$.

\section{In hand manipulation}

The results for the FSU IHM Checklist are presented according to the three components of IHM, namely translation, rotation and shift.

Translation - assess finger-to-palm and palm-to-finger translation (tasks 2-5) (Table II)

Table II indicates that all the participants in both age groups were able to pick up one dowel at a time and hold more than one dowel in the palm during finger-to-palm translation (task 2). Fifty-four

Table II: Translation movements and compensatory methods observed in six- and seven-year-old children (Tasks 2 to 5)

\begin{tabular}{|l|c|c|c|c|}
\hline \multirow{2}{*}{$\begin{array}{l}\text { Translation (finger-to-palm \& } \\
\text { palm-to-finger) }\end{array}$} & \multicolumn{2}{|c|}{$\begin{array}{c}\text { Six-year-olds } \\
(\mathbf{n}=\mathbf{5 8})\end{array}$} & \multicolumn{2}{c|}{$\begin{array}{c}\text { Seven-year- } \\
\text { olds (n= 100) }\end{array}$} \\
\cline { 2 - 5 } & $\mathbf{n}$ & $\%$ & $\mathbf{n}$ & $\%$ \\
\hline $\begin{array}{l}\text { Successful completion of } \\
\text { finger-to-palm with or without } \\
\text { compensation }\end{array}$ & 58 & 100 & 100 & 100 \\
\hline $\begin{array}{l}\text { Successful completion of } \\
\text { palm-to-finger with or without } \\
\text { compensation }\end{array}$ & 54 & 93.1 & 98 & 98.0 \\
\hline No compensatory methods used & 25 & 43.1 & 51 & 51.0 \\
\hline Compensatory methods used & $\mathbf{n = 3 3}$ & $\mathbf{n}=49$ \\
\hline Stabilise against body \& surface & 19 & 57.6 & 34 & 69.4 \\
\hline Rotate body & 3 & 9.1 & 2 & 4.1 \\
\hline Use both hands & 18 & 54.5 & 15 & 30.6 \\
\hline Fixation of arm & 6 & 18.2 & 8 & 16.3 \\
\hline Change hands & $\mathrm{I}$ & 3.0 & $\mathrm{I}$ & 2.0 \\
\hline $\begin{array}{l}\text { More than one compensatory } \\
\text { method used }\end{array}$ & 24 & 72.7 & 25 & 51 \\
\hline
\end{tabular}

(93.1 \%) of the six-year-olds and $89(89.0 \%)$ of the seven-yearolds were able to perform task 5 (while holding dowels within the palm, place them in the peg board one at a time).

Seventy Two percent of the six-year-olds used a number of compensatory methods including the most common compensatory method used by the seven-year-olds which was to stabilise against body and surface $(69.4 \%)$. The median completion time taken from task two to five was 80 seconds (range 50-145 seconds) for the six-year-olds and 65 seconds (range 43-14I seconds) for the seven-year-olds. Eleven (19.0\%) of the sixyear-olds and $28(28.0 \%)$ of the seven-year-olds dropped dowels during this task.

\section{Rotation}

\section{Simple rotation (task 7): (see Table 3)}

Table III indicates that 46 (79.3\%) of the six-year-olds and 9I (9I\%) of the seven-year-olds were able to rotate the coin between the fingertips. The task required constant contact between the coin and fingers. When the coin fell, or when the coin was moved to the palm, contact with the fingertips did not take place. Both the six-year-olds (87.5\%) and seven-year-olds (94.7\%) used more than one compensatory method. One ( $1.7 \%)$ of the six-year-olds and none of the seven-year-olds dropped the coin during the completion of this task.

Table III: Simple rotation movements and compensatory methods in the six- and seven-year- old children (task 7)

\begin{tabular}{|l|c|c|c|c|}
\hline Simple rotation & \multicolumn{2}{|c|}{$\begin{array}{c}\text { Six-year-olds } \\
\text { (n=58) }\end{array}$} & \multicolumn{2}{c|}{$\begin{array}{c}\text { Seven-year- } \\
\text { olds (n= 100) }\end{array}$} \\
\hline & $\mathbf{n}$ & $\%$ & $\mathbf{n}$ & $\%$ \\
\hline $\begin{array}{l}\text { Successful completion with or } \\
\text { without compensation }\end{array}$ & 46 & 79.3 & 91 & 91.0 \\
\hline No compensatory methods used & 50 & 86.2 & 81 & 81.0 \\
\hline Compensatory methods used & \multicolumn{2}{|c|}{$\mathbf{n = 8}$} & \multicolumn{2}{|c|}{$\mathbf{n = 1 9}$} \\
\hline Stabilise against body\& surface & 3 & 37.5 & 1 & 5.3 \\
\hline Rotate body & 0 & 0 & 0 & 0 \\
\hline Use both hands & $\mathrm{I}$ & 12.5 & 7 & 36.8 \\
\hline Fixation of arm & 3 & 37.5 & 5 & 26.3 \\
\hline Rotate wrist & 6 & 75 & 8 & 42.1 \\
\hline Change hands & 0 & 0 & 0 & 0 \\
\hline $\begin{array}{l}\text { More than one compensatory } \\
\text { method used }\end{array}$ & 7 & 87.5 & 18 & 94.7 \\
\hline
\end{tabular}

\section{Complex rotation (task I) ( see Table IV)}

The child removes five dowels from the holes in the peg board, one at a time. Using their fingertips the child was expected to turn the dowels $180^{\circ}$ and replace the dowels in its original hole.

Table IV on page 56 indicates that all the participants were able to pick up dowels, one at a time, as well as turn each dowel $180^{\circ}$. Both groups ( $81.8 \%$ of six- and $70.9 \%$ of seven-year-olds) used more than one compensatory method. Ten (I7.2\%) of the six- and six (6.0\%) of the seven-year-olds dropped a dowel during completion of this task.

\section{Complex rotation with stabilisation and shift compo-} nents (task 8): (see Table V)

Table $V$ on page 56 indicates that $42(72.4 \%)$ of the six-year-olds and $83(83.0 \%)$ of the seven-year-olds were able to rotate the dowel between their fingertips. Both the six-year-olds (72.2\%) and seven-year-olds $(52.6 \%)$ used more than one compensatory method. Three $(5.2 \%)$ of the six-year-olds and II (II.0\%) of the seven-year-olds dropped dowels during this task. 
Table IV: Complex rotation movements and compensatory methods in the six and seven-year-old children (task I)

\begin{tabular}{|l|c|c|c|c|}
\hline \multirow{2}{*}{ Complex rotation } & \multicolumn{2}{|c|}{$\begin{array}{c}\text { Six-year-olds } \\
(\mathbf{n = 5 8})\end{array}$} & \multicolumn{2}{c|}{$\begin{array}{c}\text { Seven-year- } \\
\text { olds (n= 100) }\end{array}$} \\
\cline { 2 - 5 } & $\mathbf{n}$ & $\%$ & $\mathbf{n}$ & $\%$ \\
\hline $\begin{array}{l}\text { Successful completion with or } \\
\text { without compensation }\end{array}$ & 58 & 100 & 100 & 100 \\
\hline No compensatory methods used & 36 & 62.1 & 69 & 69.0 \\
\hline Compensatory methods used & \multicolumn{2}{|c|}{$\mathbf{n = 2 2}$} & \multicolumn{2}{|c|}{$\mathbf{n = 3 1}$} \\
\hline Stabilise against body\& surface & 6 & 27.3 & 12 & 38.7 \\
\hline Rotate body & 2 & 9.1 & 5 & 16.1 \\
\hline Use both hands & 2 & 9.1 & 1 & 3.2 \\
\hline Fixation of arm & 16 & 72.7 & 18 & 58.1 \\
\hline Change hands & 1 & 4.5 & 1 & 3.2 \\
\hline $\begin{array}{l}\text { More than one compensatory } \\
\text { method used }\end{array}$ & 18 & 81.8 & 22 & 70.9 \\
\hline
\end{tabular}

Table V: Complex rotation with stabilisation in six and seven year old children (task 8 )

\begin{tabular}{|l|c|c|c|c|}
\hline \multirow{2}{*}{$\begin{array}{l}\text { Complex rotation with } \\
\text { stabilisation }\end{array}$} & \multicolumn{2}{|c|}{$\begin{array}{c}\text { Six-year-olds } \\
(\mathbf{n = 5 8})\end{array}$} & \multicolumn{2}{c|}{$\begin{array}{c}\text { Seven-year- } \\
\text { olds (n= 100) }\end{array}$} \\
\cline { 2 - 5 } & $\mathbf{n}$ & $\%$ & $\mathbf{n}$ & $\%$ \\
\hline $\begin{array}{l}\text { Successful completion with or } \\
\text { without compensation }\end{array}$ & 42 & 72.4 & 83 & 83.0 \\
\hline No compensatory methods used & 40 & 68.9 & 62 & 62.0 \\
\hline Compensatory methods used & \multicolumn{2}{|c|}{$\mathbf{n = 1 8}$} & \multicolumn{2}{|c|}{$\mathbf{n = 3 8}$} \\
\hline Stabilise against body\& surface & 6 & 33.3 & 19 & 50.0 \\
\hline Rotate body & 1 & 5.6 & 1 & 2.6 \\
\hline Use both hands & 6 & 33.3 & 6 & 15.8 \\
\hline Fixation of arm & 2 & 11.1 & 5 & 13.2 \\
\hline Change hands & 0 & 0 & 0 & 0 \\
\hline Rotate wrist & 7 & 38.9 & 12 & 31.6 \\
\hline $\begin{array}{l}\text { More than one compensatory } \\
\text { method used }\end{array}$ & 13 & 72.2 & 20 & 52.6 \\
\hline
\end{tabular}

Table VI: Shift movements and compensatory methods in six- and seven-year-old children (task 6)

\begin{tabular}{|l|c|c|c|c|}
\hline \multirow{2}{*}{ Shift movements } & \multicolumn{3}{c|}{$\begin{array}{c}\text { Six-year- } \\
\text { olds }(\mathbf{n = 5 8})\end{array}$} & \multicolumn{2}{c|}{$\begin{array}{c}\text { Seven-year- } \\
\text { olds (n= 1 00) }\end{array}$} \\
\cline { 2 - 5 } & $\mathbf{n}$ & $\%$ & $\mathbf{n}$ & $\%$ \\
\hline $\begin{array}{l}\text { Placed coin in the slot (while one } \\
\text { coin supported in hand) }\end{array}$ & 52 & 89.7 & 87 & 87.0 \\
\hline $\begin{array}{l}\text { Placed coin in the slot using thumb } \\
\text { and index finger in isolation }\end{array}$ & 35 & 60.3 & 50 & 50.0 \\
\hline No compensatory methods used & 51 & 87.9 & 96 & 96.0 \\
\hline Compensatory methods used & \multicolumn{2}{|c|}{$\mathbf{n = 7}$} & \multicolumn{2}{|c|}{$\mathbf{n = 4}$} \\
\hline Stabilise against body\& surface & 4 & 57.1 & 0 & 0 \\
\hline Rotate body & 0 & 0 & 2 & 50.0 \\
\hline Use both hands & 0 & 0 & 0 & 0 \\
\hline Fixation of arm & 3 & 42.9 & 3 & 75.0 \\
\hline Changes hands & 0 & 0 & 0 & 0 \\
\hline $\begin{array}{l}\text { More than one compensatory } \\
\text { method used }\end{array}$ & 3 & 42.9 & 4 & 100 \\
\hline
\end{tabular}

\section{Shift}

Shift with stabilisation (task 6): (see Table VI)

Table VI indicates that $52(89.7 \%)$ of the six-year-olds and 87 $(87.0 \%)$ of the seven-year-olds were able to conceal one coin in the hand, while placing the other coin in the slot. Thirty-five $(60.3 \%)$ of the six-year-olds and 50 (50.0\%) of the seven-year-olds were able to use the thumb and index finger in isolation. The most common compensatory method used by the six-year-olds (57.1\%) was to stabilise against body and surface. The seven-year-olds (100\%) used more than one compensatory method. None of the children dropped coins during this task.

Table VII shows a summary of all the individual aspects of FSU IHM that were completed successfully by the six- and seven-yearold children with or without making use of compensation.

Table VII: A summary of all IHM aspects successfully completed with or without compensation

\begin{tabular}{|l|c|c|c|c|}
\hline \multirow{2}{*}{} & \multicolumn{2}{|c|}{$\begin{array}{c}\text { Six-year-olds } \\
(\mathbf{n}=\mathbf{5 8})\end{array}$} & \multicolumn{2}{c|}{$\begin{array}{c}\text { Seven-year- } \\
\text { olds (n= 100) }\end{array}$} \\
\cline { 2 - 5 } & $\mathbf{n}$ & $\%$ & $\mathbf{n}$ & $\%$ \\
\hline Finger-to-palm translation & 58 & 100 & 100 & 100 \\
\hline Palm-to-finger translation & 54 & 93.1 & 98 & 98.0 \\
\hline Simple rotation & 46 & 79.3 & 91 & 91.1 \\
\hline Complex rotation & 58 & 100 & 100 & 100 \\
\hline $\begin{array}{l}\text { Complex rotation with } \\
\text { stabilisation }\end{array}$ & 42 & 72.4 & 83 & 83.0 \\
\hline Shift & 52 & 89.7 & 87 & 87.0 \\
\hline
\end{tabular}

\section{DISCUSSION}

To describe the components of IHM (translation, rotation and shift) in six- and seven-year-old children, the researchers determined whether a child was able to complete specific tasks, the manner in which the child performed the task and lastly, if and which compensatory methods were used during task execution.

\section{Translation}

According to Visser et al. ${ }^{6}$, four-year-old and five-year-old children are able to perform finger-to-palm translation, but palm-to-finger translation is not fully mastered. This finding corresponds with Exner' ${ }^{3}$ allusion that palm-to-finger translation is more complex than finger-to-palm translation. It was, however, observed in this study that finger-to-palm and palm-to-finger translation was consolidated in over $90 \%$ of children aged six and seven years, indicating a rapid development of palm-to-finger translation between four and six years of age. The seven-year-olds completed the translation tasks in a shorter time period than the six-year-olds, which was similar to research by Exner ${ }^{3}$ that indicated that between the ages of three and six, mastering of skills leads to a decrease in time needed to complete the tasks as the child gets older.

During the completion of the translation tasks, the six-yearolds used more compensatory methods than the seven-year-olds. This may be due to the fact that the biomechanical structures of the hand and other related motor skills are more developed in seven-year-olds. This finding correlates with those of Exner ${ }^{3}$ who indicated that IHM continues to develop until the age of twelve years. The most common compensatory method used during translation was stabilisation against the body and a surface, which occurred in both age groups, although more frequently in the seven-year-olds. Using more than one compensatory method was more common among the six-year-olds however. The fact that the six-year-olds used other compensatory methods may explain why fewer children in this age group used stabilisation against the body and a surface and dropped less dowels during the completion of this task. 


\section{Rotation}

According to Case Smith ${ }^{8}$, simple rotation should be developed in children between three-and-a-half and five-and-a-half years. This is congruent with the observation that the majority of the six- and seven-year-olds was able to perform simple and complex rotation (with or without compensation). In simple rotation the most common compensatory method used was rotation of the wrist in both age groups while fixation of the arm was more common during complex rotation. The use of more than one compensatory method occurred more amongst the seven-year-olds, possibly resulting in the seven-year-olds dropping less dowels during simple and complex rotation.

Thirteen children in each age group $(22.4 \%$ of six-year-olds and I $3 \%$ of the seven-year-olds) were unable to hold a dowel between the thumb and the index finger, while supporting another dowel with the other three fingers. Sixteen six-year-olds (27.6\%) and 17 (I7.0\%) of the seven-year-olds were unable to rotate the dowel while stabilising the other dowel. Therefore complex rotation with stabilisation was the most difficult IHM component for both age groups, in accordance with Case-Smith ${ }^{8}$, indicating that complex rotation with stabilisation is present but not yet refined in six- and seven-year-old children. The seven-year-olds used more stabilisation against the body and the surface in complex rotation with stabilisation and therefore dropped fewer dowels. This may also be ascribed to the fact that seven-year-olds rely more on cognitive abilities such as planning, and can comprehend that compensation can contribute to a higher quality of task execution.

\section{Shift with stabilisation}

Only two of the six-year-olds (3.4\%) and one of the seven-year-olds (I\%) failed to perform shift with stabilisation, indicating that this component of IHM can be considered fully developed in children of these two age groups. Thirty-five $(60.3 \%)$ of the six- and 50 $(50.0 \%)$ of the seven-year-olds did not use the thumb and index finger in isolation when placing the coin in the slot. Most of the participants used their thumb, index finger and middle finger in isolation to place the coins in the slot, which contributed to a higher quality of control when performing this task. In the previous study on four- and five-year-old children ${ }^{6}$, however, it was found that younger children who were not using the thumb and index finger in isolation had poor shift movements and perhaps not adequately developed "intrinsic hand muscles in isolation from extrinsic hand muscles" $3: 44$

Overall, the majority of the participants did not use compensatory methods to complete tasks requiring shift. The six-year-old participants who compensated used stabilisation against the body and surface, and fixation of the arm, while the seven-year-olds used rotation of the body and fixation of the arm. The seven-year-olds more frequently used compensatory methods possibly resulting in a smaller number of dowels dropping, resulting in a higher quality of task execution, and the researchers ascribe this to better cognitive planning in the older children.

\section{Pencil grip}

Based on Benbow's ${ }^{19}$ definition of efficient pencil grip, 57 (98.3\%) of the six- and 94 (94.0\%) of the seven-year-olds presented with an efficient grip. The occurrence of efficient pencil grasp observed in the majority of the six-year-olds and seven-year-olds could be related to the adequate IHM skills of these children, identified in this study. This finding was in accordance with Feder ${ }^{20}$, who stated that IHM allows a child to assume an efficient grasp and control their pencil in handwriting tasks.

It is crucial to take note that aspects such as finger-to-palm translation and complex rotation had been mastered by six-yearolds and seven-year-olds, and are therefore considered as the moderately difficult IHM components that are consolidated after five years of age. Similar performance can thus be expected from other typically developed children in this age group. However, simple rotation and complex rotation with stabilisation appear to be the most difficult IHM aspects for the six-year-olds, and are not necessarily indicative of dysfunction or delays.

\section{Limitations of the study}

The limitations identified in this study were the poor response from schools and parents which limited the study population to I 58 children. However, the number of children compared well to the group of 195 participants from the previous study ${ }^{6}$. Although a multicultural group of children constituted the study population, only children with English as their primary language of education, regardless of their home language and culture, were included in the study. Consequently, the results of this study cannot be generalised to the South African population. A factor that was not taken into consideration was the potential influence of recording video footage on the children's performance during the assessment procedures and how it could have affected the results.

\section{CONCLUSION}

No measuring instruments, standardised on the South African population with age-related norms to evaluate all IHM components, are currently available, for four- to seven-years-old children. The lack of such instruments results in a lack of accurate assessment and interpretation of IHM according to age, which influences intervention planning for IHM in occupational therapy.

This article reports on the IHM skills of six- and seven-year-old South African children using the FSU IHM Checklist the development of which was reported in a previous research on IHM skills of four- and five-year-old children ${ }^{6}$. The results of this study indicated that most children in both age groups could perform palm-to- finger translation, complex rotation and shift with stabilisation, with simple rotation and finger-to-palm translation improving from six year-olds to seven-year-olds. It appears that children use fewer compensatory methods in IHM tasks, as they get older. Complex rotation with stabilisation appeared to be the most difficult task for all age groups and is not consolidated by seven years of age.

These IHM standards make a unique contribution to the current state of knowledge in the profession, and the collective results from the two studies on IHM can be used as a base-line for IHM in clinical decisions for four-year-old to seven-year-old children. This information is valuable in informing practice, despite the fact that the FSU IHM Observation Checklist has not yet been standardised on the South African population. It provides a practical interim solution through a comprehensive Checklist for use with children that is inexpensive, easily reproducible and quick to administer. This checklist can be used to inform evidence-based practice in occupational therapy.

However, further recommendations on amendments to the IHM Observation Checklist following this study include: the addition of questions on dropping dowels in tasks $2-5$, and the development of a user-friendly instructors' manual to be used with the observation checklist. For future research, it is recommended that a standardised measurement tool, with 6 month intervals (and not just year intervals) and using a broader spectrum of ages and populations, be developed for the South African population. In addition, IHM intervention studies in follow-up to the IHM assessment research are recommended.

\section{ACKNOWLEDGEMENTS}

Dr. Christel Troskie-de Bruin from ASEV Research and Development Consultants and Dr. Daleen Struwig, Faculty of Health Sciences, UFS, are acknowledged for technical and editorial preparation of the manuscript.

\section{REFERENCES}

I. Case-Smith J. Fine motor outcomes in pre-primary children who receive occupational therapy services. American Journal of Occupational Therapy, 1996; 50: 52-60.

2. Case-Smith J, Pehoski C. Development of Hand Skills in the Child. Bethesda, MD: American Occupational Therapy Association, Inc; 1992: 35-44. 
3. Exner CE. In-hand manipulation skills. In: Case-smith J, Pehoski C. editors. Development of Hand Skills in the Child. Bethesda, MD: American Occupational Therapy Association, Inc; 1992: 35-40.

4. Miles Breslin DM, Exner CE. Construct validity of the IHM test: a discriminant analysis with children without disability and children with spastic diplegia. American Journal of Occupational Therapy, 1999; 53(4): 38I-386.

5. Pehosi C, Henderson A, Tickle-Degnen L. In-hand manipulation in young children: rotation of objects in the fingers. American Journal of Occupational Therapy, 1997; 5I(7): 544-552.

6. Visser M, Nel M, De Vries J, Heimes N, Klopper E, Olën K, van Coller. In-hand manipulation of children aged four and five-years-old: translation, rotation, and shift movements. South African Journal of Occupational Therapy, 2014; 44(2): 22-28.

7. Pont K, Wallen M, Bundy A, Case-Smth J. Reliability and validity of the Test of In-Hand Manipulation in children ages 5 to 6 years. American Journal of Occupational Therapy, 2008; 62(4): 384-392.

8. Case-Smith J, O'Brien JC. Occupational Therapy for Children. $6^{\text {th }}$ ed. Missouri: Mosby Elsevier; 2010: 275-312.

9. Pont K, Wallen M, Bundy A. Conceptualising a modified system for classification of in-hand manipulation. Australian Occupational Therapy Journal, 2009; 56(I): 2-15.

10. American Occupational Therapy Association. Occupational Therapy Practice Framework: Domain and Process. 3rd ed. American Journal of Occupational Therapy, 20I4; 68 (supplement I).

II. Long C, Conrad PW, Hall EA, Furler SL. Intrinsic-extrinsic muscle control of the hand in power grip and precision handling. Journal of Bone and Joint Surgery, 1970; 52(5): 845-855.

12. Bly L. Motor Skills Acquisition in the First Year. An Illustrated Guide to Normal Development. I ${ }^{\text {st }}$ ed. Tucson: Therapy Skill Builders; 1994.

13. Mulligan SE. Occupational Therapy Evaluation for Children: A Pocket Guide. Philadelphia: Lippincott Williams \& Wilkins; 2003.

14. Case-Smith J. Comparison of in-hand manipulation skills in children with and without fine motor delays. Occupational Therapy Journal of Research, 1993; 13(2): 87-100.

15. Exner CE. Clinical interpretation of in-hand manipulation in young children: translation of movements. American Journal of Occupational Therapy, 1997; 5I(9): 729-732.

16. Katyal P, Raja K. Development of a Test of In-Hand Manipulation for children. Journal of Hand Therapy, 2010; 23(4): 432-433.

17. Humphry R, Jewell K, Rosenberger RC. Development of in-hand manipulation and relationship with activities. American Journal of Occupational Therapy, 1994; 49(8): 763-770.

18. Cornhill H, Case-Smith J. Factors that relate to good and poor handwriting. American Journal of Occupational Therapy, 1996; 50(9): 732-739.

19. Benbow M. Neurokinesthetic Approach to Hand Function and Handwriting. Albuquerque, NM: Clinician's view; 1995: 23-24.

20. Feder KP, Majnemer A. Handwriting development, competency and intervention. Developmental Medicine and Child Neurology, 2007; 49(4): 3।2-317. 